\title{
Multiobjective portfolio optimization of ARMA-GARCH time series based on experimental designs
}

\author{
R.R.A. Mendes ${ }^{\text {a }}$, A.P. Paiva ${ }^{\text {b }}$, R.S. Peruchi ${ }^{\text {b }}$, P.P. Balestrassi ${ }^{\text {b,* }}$, R.C. Leme $^{\text {b }}$, M.B. Silva ${ }^{\text {c }}$ \\ ${ }^{a}$ Federal Institute of Education, Science and Technology-South of Minas Gerais, Estrada do Aeroporto 1730, Pouso Alegre 37550-000, MG, Brazil \\ ${ }^{\mathrm{b}}$ Federal University of Itajubá, Av BPS, 1303, Itajubá 37500-903, MG, Brazil \\ c São Paulo State University, Av. Dr. Ariberto Pereira da Cunha, 333, Guaratinguetá 12516-410, SP, Brazil
}

\section{A R T I C L E I N F O}

\section{Available online 13 May 2015}

Keywords:

Mixture design of experiments ARMA-GARCH models

Multiobjective portfolio optimization

Entropy

\begin{abstract}
A B S T R A C T
The modern portfolio theory has been trying to determine how an investor might allocate assets among the possible investments options. Since the seminal contribution provided by Harry Markowitz's theory of portfolio selection, several other tools and procedures have been proposed to deal with return-risk trade-off. Furthermore, diversification across sources of returns and risks based on entropy indexes is another pivotal aspect in portfolio management. An efficient approach to model these portfolio properties with the proportion of each asset can be obtained according to mixture design of experiments. Desirability method can be applied to optimize this nonlinear multiobjective problem. Nevertheless, a tuning procedure is required, since preference articulation parameters in desirability algorithm are unknown a priori. As a result, a computer-aided desirability tuning method is proposed to find an optimal portfolio with time series of returns and risks modeled by ARMA-GARCH models. To assess the proposal feasibility, the method is tested with a heteroskedastic dataset formed by weekly world crude oil spot prices and returns. Computer-aided desirability tuning was able to enhance the global desirability by $79 \%$ in relation to the result with no tuning procedure.
\end{abstract}

(c) 2015 Elsevier Ltd. All rights reserved.

\section{Introduction}

The allocation of different assets in a profitable portfolio is one of the major interesting issues in energy market management. The risks associated to this sector are mainly linked with the high volatility of fossil fuels, electricity and $\mathrm{CO}_{2}$ emission prices, which evolve over time and are difficult to predict [1]. To quantify this time-varying variance, GARCH (generalized autoregressive conditional heteroskedasticity) is the time series technique applied to model the serial dependence of volatility [2]. During the period of extreme oil price volatility in India, July 2nd, 2007-November 28th, 2008, Ghosh [3] employed GARCH and EGARCH models to investigate the impact of oil price shocks on nominal exchange rate. Charles and Darné [4] assessed how shocks (outliers) affect volatility over time by using a new semi-parametric test based on conditional heteroskedastic models. It was concluded that outliers associated with particular event patterns can bias the regularity and non-negativity conditions of GARCH-type models, the detection of structural breaks in volatility, and the parameters' estimates of the equation governing volatility dynamics. Treating weekly crude oil spot price in eleven international markets over

\footnotetext{
* Corresponding author. Tel.: +55 3588776958.

E-mail address: pedro@unifei.edu.br (P.P. Balestrassi).
}

the 1997-2009 period, Mohammadi and Su [5] highlighted the goodness-of-fit of MA(1)-GARCH (1,1) for modeling and forecasting the conditional mean and volatility. Hou and Suardi [6] used a nonparametric GARCH model to capture the return volatility for crude oil market. Chang et al. [7] discussed the use of GARCH $(1,1)$ to estimate the variance (volatility) one-day-ahead forecasting for a portfolio consisting of crude oil, corn and soybeans. The authors calculated the weight of each component in the portfolio, assuming some constraints related to the minimal values of each component that are related to the production capacity.

As an optimal criterion to choose assets, Mean-Variance Portfolio (MVP) optimization of Markowitz [8,9], considers the minimization of the portfolio variance and maximization of the expected return [10,11]. A pivotal issue observed in MVP literature is related to forecasted values in a portfolio composition using ARMA (autoregressive moving average) models to estimate the returns $[6,5]$ and $\operatorname{GARCH}(1,1)$ models to predict the variance or portfolio volatility [12-17] or, in more comprehensive cases, using both ARMA-GARCH or its variations [18]. Hlouskova et al. [19] employed an ARMA-GARCH prediction for quarterly and monthly values resulting in a rebalanced portfolio that outperforms the traditional ones. The authors also present some concerns about prediction or forecasting errors. Moreover, other prediction algorithms as neural networks are combined to an optimization MVP routine. 


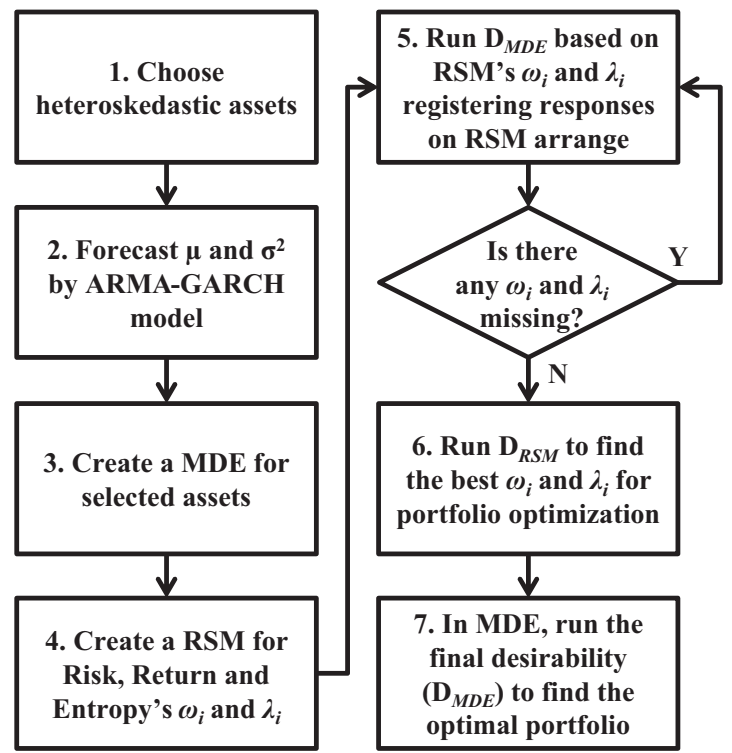

Fig. 1. Computer-aided desirability tuning method.

The problem of Markowitz's mean-variance model is due to portfolios highly concentrated on a limited number of assets, which deviates from the original purpose of diversification [20]. As entropy is a well-known measure of diversity, many scholars apply it to the portfolio selection theory [21]. Philippatos and Wilson [22] have affirmed that the mean-entropy portfolios were consistent with the Markowitz full-covariance and the Sharpe single-index models. Yu et al. [23] evaluated the performance of the portfolio selections incorporating different entropy measures by applying multiple criteria method, improving the feasibility of models considering the impact of short-sale constraints and transaction costs on portfolios.

The current availability of optimization packages customized for portfolio management has been encouraging investor to apply mean-variance optimization in their portfolio construction process [20]. Oliveira et al. [24] have used mixture design of experiments (MDE) to model asset proportions in relation to portfolio's risk and return. As an alternative of using traditional linear programming, the authors have combined multi-response and nonlinear objective functions into a desirability algorithm for portfolio's optimization. In such cases, a suitable compromise solution may be obtained by incorporating decision maker's preference into the problem. Jeong and Kim [25] proposed an interactive desirability function approach (IDFA) to facilitate the preference articulation process allowing the decision maker to adjust the desirability function parameters (shape, bound and target) in a wellstructured framework. Although the authors have argued that their interactive method was highly effective in generating compromised solutions, it is widely known that experimental designs are notably better approaches for building causal relationships.

Taking into consideration the aforementioned literature, a suitable approach to help practitioners and investors, in energy market, to obtain a profitable portfolio should: (a) include a convex multiobjective problem; (b) use a well-fitted risk and return models for an one-step-ahead predicted values; (c) embody a time series technique capable of detecting volatility, co-movements and time-varying conditional correlation; (d) promote the portfolio diversification and (e), allow the investor to encompass some risk aversion metric. These requirements can be achieved representing the expected portfolio risk, return and entropy by their respective response surfaces obtained through Mixture Design of Experiments [24]. In order to solve this multiobjective portfolio problem, the desirability algorithm can be implemented by using optimal parameters, according to an effective tuning procedure. Therefore, this paper aims to propose an optimal desirability algorithm capable of finding a suitable portfolio for a given amount of assets, considering their respective conditional risk, return and diversity.

The remainder of this paper is structured as follows. Section 2 presents an overview of statistical and optimization techniques applied to portfolio selection when the dataset is well fitted by ARMA-GARCH models. Section 3 details the proposed method to determine an optimal portfolio considering not only MDE and RSM (response surface methodology) designs, but also desirability functions. Section 4 shows the application of this method on crude oil sector. Finally, Section 5 presents the main findings of this paper.

\section{Portfolio optimization}

\subsection{Markowitz mean-variance model}

The major breakthrough in portfolio optimization was provided by Harry Markowitz and his modern theory of portfolio selection [8]. The author suggested that investor should allocate funds among investments based on the risk-return trade-off. This financial decision-making process can be formulated as a meanvariance optimization problem, in which the expected return must be maximized with variance as small as possible [20]. As suggested by Anagnostopoulos and Mamanis [26], Markowitz meanvariance approach can be written as the following multiobjective optimization problem:

$$
\begin{aligned}
& \operatorname{Min} \rho(x)=\sum_{i=1}^{n} \sum_{j=1}^{n} x_{i} x_{j} \sigma_{i j} \\
& \operatorname{Max} \mu(x)=\sum_{i=1}^{n} x_{i} \mu_{i} \\
& \text { s.t. : } \quad \sum_{i=1}^{n} x_{i}=1 \\
& \sum_{i=1}^{n} \delta_{i} \leq K,
\end{aligned}
$$

$l_{i} \delta_{i} \leq x_{i} \leq u_{i} \delta_{i} \quad i=1,2, \ldots, n$

$\delta_{i} \in\{0,1\} \quad i=1,2, \ldots, n$

where $n$ is the number of assets included in the portfolio, $x_{i}$ is the proportion of each asset $i, \mu(x)$ is the expected return, $\sigma_{i j}$ is the covariance between the returns of assets $i$ and $j ; \rho(x)$ is the portfolio risk, $\delta_{i}$ is a binary variable which assumes the values 0 or 1 if the asset is chosen or not; $K$ is the number of assets (or series) available; $l_{i}$ and $u_{i}$ are respectively the lower and upper bounds for the proportion of each asset $i$.

\subsection{Heteroskedastic time series modeling}

Some authors $[5,18,19]$ highlighted that GARCH models outperforms the traditional techniques such as moving average, exponential smoothing and linear regression in the modeling and forecasting task of conditional time series. Hence, assuming that the series of returns of each component $q$ is heteroskedastic, its value can be modeled and forecasted by a GARCH model. According to Pham and Yang [27], the $\operatorname{ARMA}(r, m)-\mathrm{GARCH}(p, q)$ 

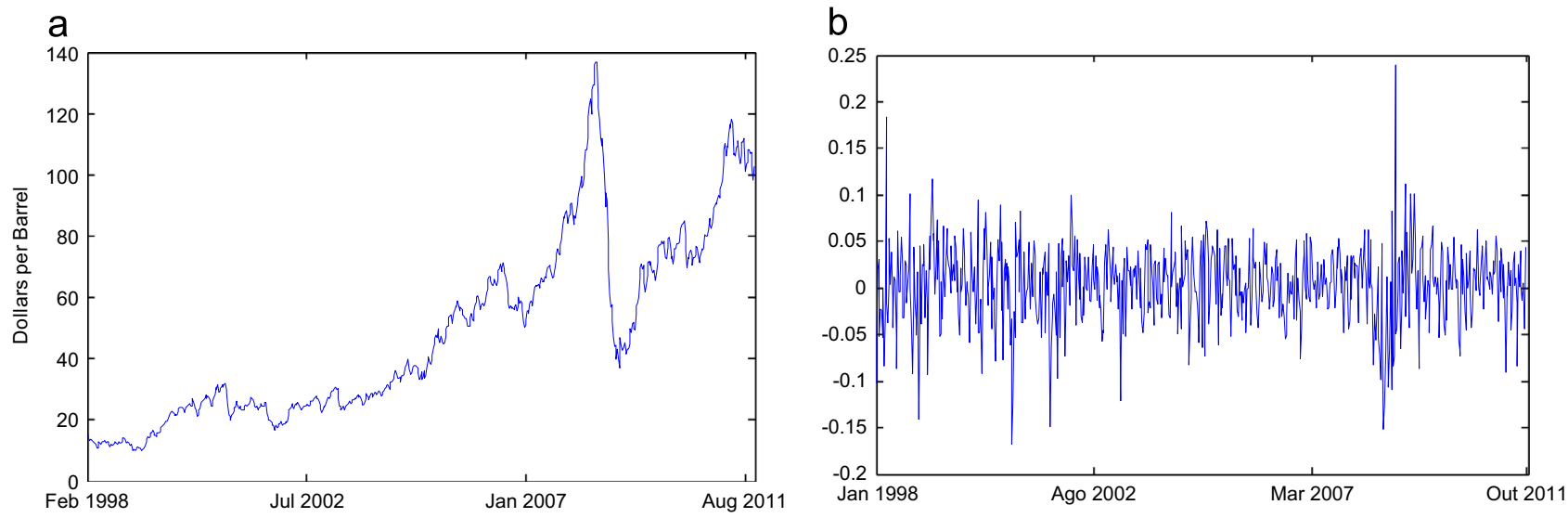

Fig. 2. Dubai Fateh time series.

Table 1

Summary statistics for returns of crude oil markets.

\begin{tabular}{lrrrr}
\hline Variable & \multicolumn{1}{l}{ Dubai } & \multicolumn{1}{l}{ China } & Indonesia & Venezuela \\
\hline Mean & 0.00279 & 0.00277 & 0.00284 & 0.00269 \\
StDev & 0.04148 & 0.04290 & 0.04364 & 0.04852 \\
Minimum & -0.16816 & -0.24888 & -0.25799 & -0.21996 \\
Maximum & 0.24007 & 0.15194 & 0.20978 & 0.19694 \\
Skewness & -0.24650 & -0.66846 & -0.51186 & -0.48673 \\
Kurtosis & 2.79400 & 2.94339 & 3.13425 & 1.78357 \\
\hline
\end{tabular}

Table 2

Summary statistics of returns up to 20 lags.

\begin{tabular}{lllll}
\hline Variable & Dubai & China & Indonesia & Venezuela \\
\hline Ljung-Box & 14.1402 & 18.6552 & 16.2289 & 13.3007 \\
Engle's ARCH & 15.0486 & 17.8899 & 16.3519 & 14.7706 \\
\hline
\end{tabular}

model can be estimated for a univariate process as:

$\sigma_{t}^{2}=\omega_{i}+\sum_{j=1}^{p} \beta_{i} \sigma_{t-j}^{2}+\sum_{i=1}^{q} \alpha_{i} \varepsilon_{t-j}^{2}$

$y_{t}=c+\sum_{i=1}^{r} \varphi_{i} y_{t-i}+\sum_{j=1}^{m} \theta_{i} \varepsilon_{t-j}+\varepsilon_{t} \varepsilon_{t} \sim N\left(0, \sigma_{t}^{2}\right)$

$\varepsilon_{t}=\sigma_{t} z_{t}, z_{t} \sim N(0,1)$

For a given instant $t$, the returns of $i$ assets modeled as ARMA $(1,1)$ and their respective conditional variances (or risks) as a GARCH $(1,1)$ can be written as such:

$\sigma_{i, t}^{2}=h_{i t}=\omega_{i}+\alpha_{1} \varepsilon_{t-1}^{2}+\beta_{1} \sigma_{t-1}^{2}$

$y_{i, t}=c+\varphi_{1} y_{i, t-1}+\theta_{1} \varepsilon_{i, t-1}+\varepsilon_{i, t}$

where $h_{i t}$ is the conditional variance of volatility of $\varepsilon_{i}$ for the asset $i$ at time $t$, the coefficients $\omega, \alpha$ and $\beta$ are related to the innovations $\varepsilon_{t-j}^{2}$.

Taking the covariance term of two risk assets $i$ and $j\left(\sigma_{i j}\right)$ written in terms of a conditional covariance when the asset returns are heteroskedastics, it may be assumed that $\sigma_{i j}=\rho_{i j} \sqrt{h_{i i} h_{j j}}$, where $h_{i i}$ is the variance of asset $i$ and $h_{j j}$ is the variance of asset $j ; \rho_{i j}$ is the conditional correlation. Then, since the portfolio may be formed by one-step-ahead forecasting values, the portfolio risk can be established using Constant (CCC) or Dynamic Conditional Correlation (DCC) concepts [13,16,28,29].
Table 3

Parameter ARMA-GARCH for markets.

\begin{tabular}{lllll}
\hline Parameters & Dubai & China & Indonesia & Venezuela \\
\hline$C$ & 0.006165 & 0.004589 & 0.005042 & 0.005692 \\
$\mathrm{AR}(1)$ & -0.462880 & -0.113180 & -0.150610 & -0.458030 \\
$\mathrm{MA}(1)$ & 0.683240 & 0.434770 & 0.418500 & 0.645900 \\
$K$ & $5.5192 \mathrm{e}-05$ & $1.2999 \mathrm{e}-05$ & $1.4414 \mathrm{e}-05$ & $9.5695 \mathrm{e}-05$ \\
GARCH(1) & 0.886030 & 0.812940 & 0.812030 & 0.902760 \\
ARCH(1) & 0.078568 & 0.106320 & 0.102760 & 0.053396 \\
\hline
\end{tabular}

Table 4

One-step-ahead returns forecasting using ARMA-GARCH models.

\begin{tabular}{lllll}
\hline Parameters & Dubai & China & Indonesia & Venezuela \\
\hline$\hat{\sigma}_{t}^{2}$ & 0.0360 & 0.0346 & 0.0365 & 0.0432 \\
$\hat{y}_{i, t}$ & 0.0033 & 0.0094 & 0.0084 & 0.0167 \\
\hline
\end{tabular}

The constant conditional variance-covariance matrix can be written as:

$H_{t}=\left[\begin{array}{cccc}\sigma_{11, t}^{2} & \sigma_{12, t}^{2} & \cdots & \sigma_{1 n, t}^{2} \\ \sigma_{12, t}^{2} & \sigma_{22, t}^{2} & \cdots & \sigma_{2 n, t}^{2} \\ \vdots & \vdots & \ddots & \vdots \\ \sigma_{1 n, t}^{2} & \sigma_{2 n, t}^{2} & \cdots & \sigma_{n n, t}^{2}\end{array}\right]$

$\sigma_{i, t}^{2}=h_{i t}=\omega_{i}+\sum_{i=1}^{p} \alpha_{i} \varepsilon_{t-i}^{2}+\sum_{j=1}^{q} \beta_{j} \sigma_{t-j}^{2}$

$\sigma_{i j, t}=\rho_{i j} \sigma_{i, t} \sigma_{j, t} \quad i, j=1, \ldots, n, \quad i \neq j$

$H_{t}=D_{t} R D_{t}$

According to Asai and McAleer [30] CCC and DCC structures can be both used for purposes of determining optimal portfolio and risk management strategies. The conditional volatilities from multivariate MGARCH models can be used to construct optimal portfolio weights [31] and their values influence greatly the optimal weights. Kroner and $\mathrm{Ng}$ [31], established that the optimal weights of a portfolio formed with heteroskedastic assets can be obtained as:

$x_{i j, t}=\frac{h_{j j, t}-h_{i j, t}}{h_{i i, t}-2 h_{i j, t}+h_{j j, t}}$

It can be shown that Eq. (15) is obtained with the minimization of $\sum_{i=1}^{k} x_{i}^{2} h_{i i}+2\left(\sum_{i<j}^{n} \sum x_{i} x_{j} h_{i j}\right)$ for only two assets and with weights equals to $x_{i}$ and $x_{j}=\left(1-x_{i}\right)$. Since the variance of the series is 
a

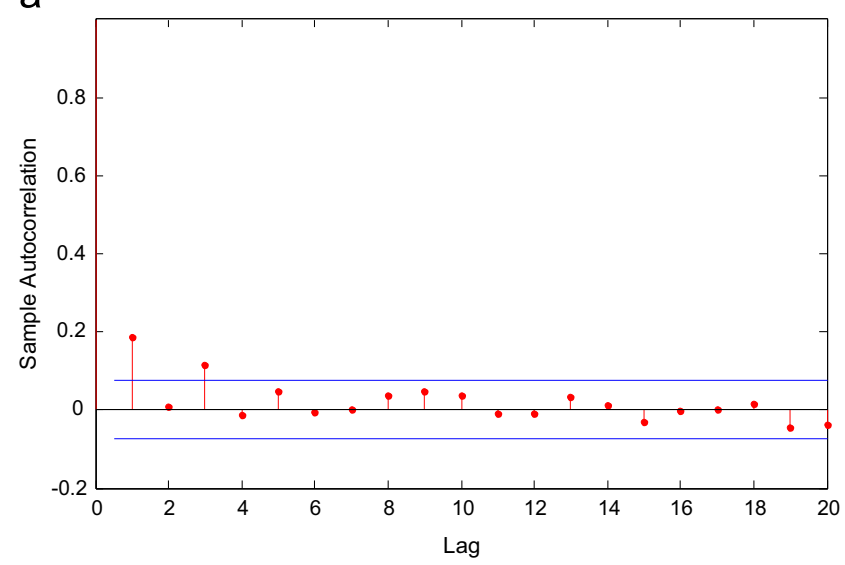

b

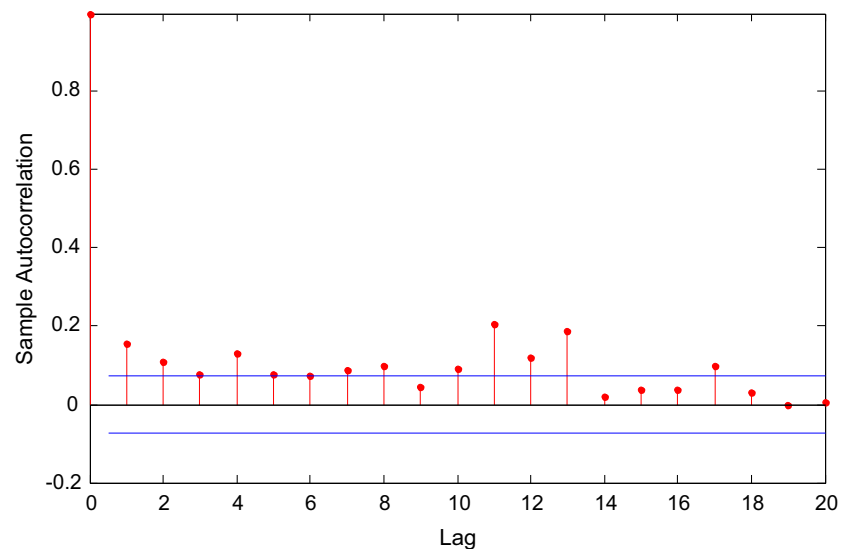

Fig. 3. Dubai Fateh autocorrelation functions.

Table 5

MDE for modeling risk, return and entropy based on asset proportions.

\begin{tabular}{|c|c|c|c|c|c|c|c|}
\hline \multirow[b]{2}{*}{ \# } & \multicolumn{4}{|c|}{ Mixture proportions } & \multicolumn{3}{|c|}{ Portfolio properties } \\
\hline & Dubai & China & Indonesia & Venezuela & Risk & Return & Entropy \\
\hline 1 & 0.8500 & 0.0500 & 0.0500 & 0.0500 & 0.03182 & -0.00315 & 0.58750 \\
\hline 2 & 0.0500 & 0.8500 & 0.0500 & 0.0500 & 0.03441 & -0.00139 & 0.58750 \\
\hline 3 & 0.0500 & 0.0500 & 0.8500 & 0.0500 & 0.03546 & -0.00035 & 0.58750 \\
\hline 4 & 0.0500 & 0.0500 & 0.0500 & 0.8500 & 0.03568 & -0.00371 & 0.58750 \\
\hline 5 & 0.4500 & 0.4500 & 0.0500 & 0.0500 & 0.03122 & -0.00227 & 1.01823 \\
\hline 6 & 0.4500 & 0.0500 & 0.4500 & 0.0500 & 0.03156 & -0.00175 & 1.01823 \\
\hline 7 & 0.4500 & 0.0500 & 0.0500 & 0.4500 & 0.03276 & -0.00343 & 1.01823 \\
\hline 8 & 0.0500 & 0.4500 & 0.4500 & 0.0500 & 0.03467 & -0.00087 & 1.01823 \\
\hline 9 & 0.0500 & 0.4500 & 0.0500 & 0.4500 & 0.03297 & -0.00255 & 1.01823 \\
\hline 10 & 0.0500 & 0.0500 & 0.4500 & 0.4500 & 0.03343 & -0.00203 & 1.01823 \\
\hline 11 & 0.3167 & 0.3167 & 0.3167 & 0.0500 & 0.03201 & -0.00163 & 1.24220 \\
\hline 12 & 0.3167 & 0.3167 & 0.0500 & 0.3167 & 0.03176 & -0.00275 & 1.24220 \\
\hline 13 & 0.3167 & 0.0500 & 0.3167 & 0.3167 & 0.03200 & -0.00240 & 1.24220 \\
\hline 14 & 0.0500 & 0.3167 & 0.3167 & 0.3167 & 0.03319 & -0.00182 & 1.24220 \\
\hline 15 & 0.2500 & 0.2500 & 0.2500 & 0.2500 & 0.03198 & -0.00215 & 1.38629 \\
\hline 16 & 0.5500 & 0.1500 & 0.1500 & 0.1500 & 0.03125 & -0.00265 & 1.18251 \\
\hline 17 & 0.1500 & 0.5500 & 0.1500 & 0.1500 & 0.03273 & -0.00177 & 1.18251 \\
\hline 18 & 0.1500 & 0.1500 & 0.5500 & 0.1500 & 0.03319 & -0.00125 & 1.18251 \\
\hline 19 & 0.1500 & 0.1500 & 0.1500 & 0.5500 & 0.03312 & -0.00293 & 1.18251 \\
\hline
\end{tabular}

conditional (heteroskedastic assets), the correlation is also conditional. Then, standardized conditional residuals can be obtained by:

$u_{i t}=\frac{\varepsilon_{i t}}{\left(\sqrt{h_{i i t}}\right)}$

the CCC between assets $i$ and $j$ at a time $t-1$ can be written according to Higgs [16] and Bauwens et al. [13] and can be determined as:

$\Psi_{i j, t-1}=\frac{\sum_{m=1}^{M} u_{i, t-m} u_{j, t-m}}{\sqrt{\left(\sum_{m=1}^{M} u_{i, t-m}^{2}\right) \times\left(\sum_{m=1}^{M} u_{j, t-m}^{2}\right)}}$

Some modifications in the traditional MVP should be introduced taking into consideration the general aspects of ARMAGARCH models. Therefore, the original multiobjective portfolio optimization in Eqs. (1) and (2) can be updated to the heteroskedastic portfolio as such:

Min $\quad \sigma_{P-\mathrm{GARCH}}^{2}=\sum_{i=1}^{k} x_{i}^{2} h_{i i}+2\left(\sum_{i<j}^{n} \sum x_{i} x_{j} \Psi_{i j, t-1} h_{i} h_{j}\right)$
$\operatorname{Max} \quad E(x)=\sum_{i=1}^{n} x_{i} y_{t}=\sum_{i=1}^{n} x_{i}\left(\mu+\sqrt{h_{i i}} \varepsilon_{t}\right)$

s.t. : $\quad \sum_{i=1}^{n} x_{i}=1$

The constraints defined by Eqs. (4)-(6) remain the same.

\subsection{Entropy}

Originally, entropy was utilized in thermodynamics, however, its advantages in measuring risk and describing distributions have been extensively taken into account in finance theory [21]. In the field of portfolio selection, entropy was initially applied to measure portfolio's risk by replacing the variance in mean-variance models [22]. On the other hand, some authors argued that one of the shortfalls of Markowitz's MVP is the generation of portfolios highly concentrated on few assets with poor out-of-sample performance [21,32-35]. To deal with the diversification problem, the maximization of Shannon's Entropy index can be employed to improve the portfolio's diversity [32,33]. The Shannon's Entropy index, also called as Shannon-Wiener Index, is one of several diversity indices used to measure diversity in categorical data. It is simply the information entropy of the distribution, treating species as symbols and their relative population sizes as the probability [36]. According to Grubb et al. [37] the ShannonWeiner index was considered satisfactory due to incorporate the concepts of variety and balance. The principle of Maximum Entropy determines the least-informative probability distribution for a random variable $X$ given some prior information about $X$. For example, if the mean and variance of $X$ are available, the continuous probability distribution that maximizes the Shannon differential entropy is the normal distribution. According to Krokhnal et al. [38], Shannon differential entropy can be written as:

$S(x)=-\int_{-\infty}^{\infty} f_{X}(t) \log f_{X}(t) d t$

Since portfolio's weights are proportions, $f_{X}(t)$ follows a discrete probability distribution and the Maximum Entropy in Eq. (21) becomes [39]:

$S(x)=-\sum_{i=1}^{n+1} f_{X}(t) \log f_{X}(t)=-\sum_{i=1}^{n+1} x_{i} \log \left(x_{i}\right)$

where $x_{i}$ are the weights (or proportions) chosen for each asset $i$. The form of Eq. (22) is known as the Shannon-Weiner Index $[37,39,40]$. Several researchers used the Shannon's entropy index 
a

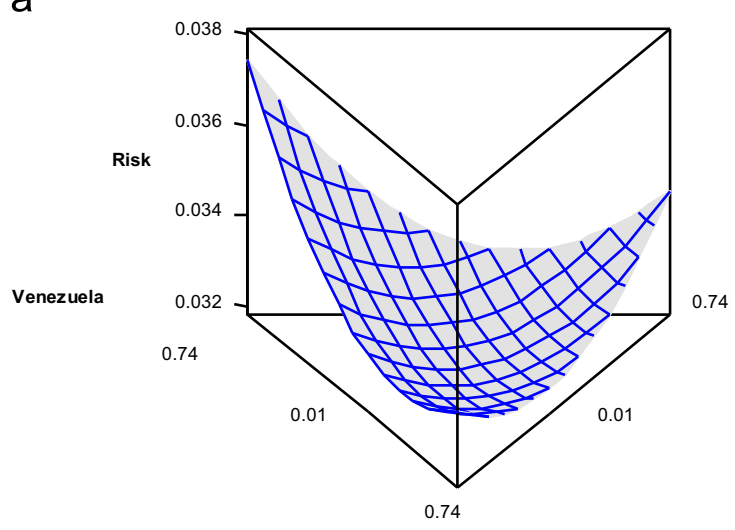

Dubai b
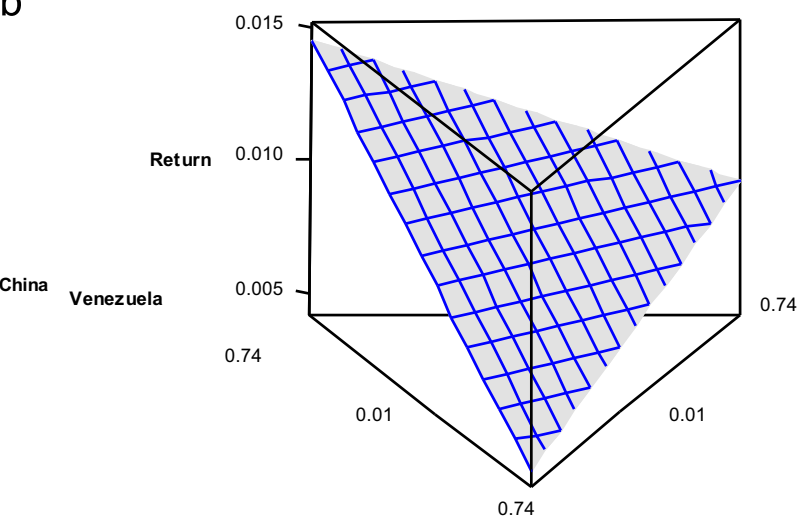

Dubai

C

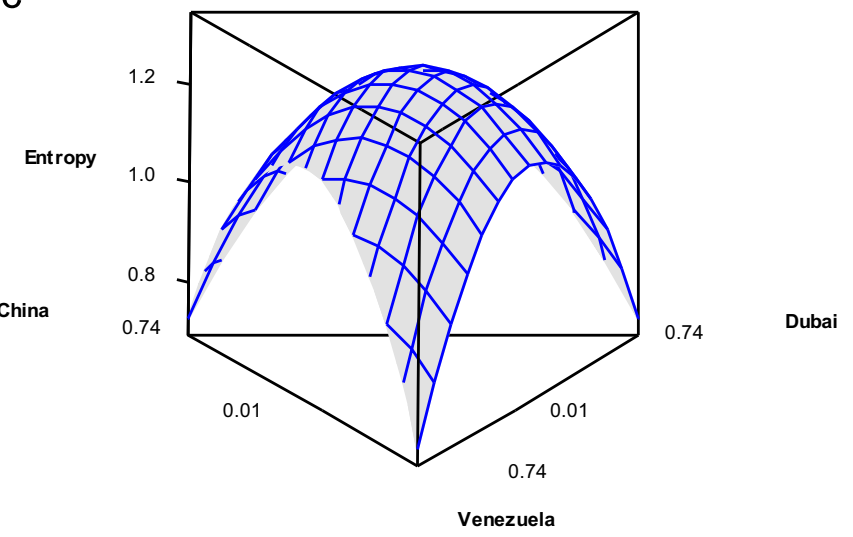

Fig. 4. Mixture response surfaces for (a) risk, (b) return and (c) entropy.

in the portfolio optimization task mainly considering the multiobjective approach [32-34].

\subsection{Mixture design of experiment}

Classical mixture designs are special kind of response surfaces in which the factors involved in the experimentation are proportions of components in a mixture and for which the sum must be constrained to a certain value. As a main advantage, the polynomial is a convex function [41]. When compared to MVP approach, it is straightforward that the mean-variance equations may be written as a mixture response surface, where the amounts of capital investment in $q$ assets are defined by the type of mixture design, such as an extreme vertices, simplex lattice, or simplex centroid $[24,41]$. Suppose that the weights or amounts $x_{i}$ of the MVP model could be considered proportions of a mixture whose sum of weights is unitary or constrained to a specific bound $\xi$. Since the proportions are dependent, the constraints represented by Eqs. (4)-(6) are no longer needed in a MDE approach in a portfolio allocation task.

The heteroskedastic portfolio described in Eqs. (18)-(20) can be modified by adding entropy function $S(x)$ shown in Eq. (22). This third objective function must be maximized and the original multiobjective portfolio optimization scheme is now written as follows:

Min

$$
\sigma_{P-\mathrm{GARCH}}^{2}=\sum_{i=1}^{k} x_{i}^{2} h_{i i}+2\left(\sum_{i<j}^{n} \sum x_{i} x_{j} \Psi_{i j, t-1} h_{i} h_{j}\right)
$$

$\operatorname{Max} \quad E(x)=\sum_{i=1}^{n} x_{i} y_{t}$

$\operatorname{Max} S(x)=-\sum_{i=1}^{n+1} x_{i} \log \left(x_{i}\right)$

s.t. : $\quad \sum_{i=1}^{n} x_{i}=1$

with:

$\sigma_{i, t}^{2}=h_{i t}=\omega_{i}+\alpha_{1} \varepsilon_{t-1}^{2}+\beta_{1} \sigma_{t-1}^{2}$

$y_{i, t}=c+\varphi_{1} y_{i, t-1}+\theta_{1} \varepsilon_{i, t-1}+\varepsilon_{i, t}$

Considering the response surfaces established for $\sigma_{t}^{2}, E(x)$ and $S(x)$, respectively as $f_{1}\left(\sigma_{t}^{2}\right), f_{2}(E(x))$ and $f_{3}(S(x))$ and also using a mixture design of experiments, the new three objective functions used in multiobjective MVP can be obtained as such:

$$
\begin{gathered}
\left\{f_{1}\left(\sigma_{t}^{2}\right), f_{2}(E(x)), f_{3}(S(x))\right\}_{\text {Portfolio }}=\sum_{i=1}^{q} \beta_{i}^{*} x_{i} \\
+\sum \sum_{i<j}^{q} \beta_{i j}^{*} x_{i} x_{j}+\sum \sum_{i<j<k} \sum^{q} \beta_{i j k}^{*} x_{i} x_{j} x_{k}
\end{gathered}
$$

The coefficients $\beta_{i}^{*}$ show how each component contributes to the response variable; $\beta_{i j}^{*}$ indicates what is the combined effect of components $i$ and $j$. Indeed, for the linear model $\beta_{i j}^{*}=\beta_{0}+\beta_{i}$ and for the quadratic model, it is possible to write: $\beta_{i}^{*}=\beta_{0}+\beta_{i}+\beta_{i i}$ and $\beta_{i j}^{*}=\beta_{i j}-\beta_{i i}-\beta_{j j}$. These coefficients are estimated using the Ordinary Least Squares (OLS) algorithm. 
Table 6

Feasible solution before method implementation.

\begin{tabular}{|c|c|c|c|c|c|c|c|c|}
\hline \multicolumn{2}{|c|}{ Objective functions } & \multicolumn{3}{|l|}{ Bounds } & \multicolumn{4}{|c|}{ Prediction } \\
\hline Function & Goal & Lower & Target & Upper & $\omega_{i}$ & $\lambda_{i}$ & Value & Desirability \\
\hline Risk & Minimize & 0.03198 & 0.03198 & 0.03544 & 1 & 1 & 0.03328 & 0.6248 \\
\hline Return & Maximize & 0.00945 & 0.01634 & 0.01634 & 1 & 1 & 0.01169 & 0.3258 \\
\hline \multirow[t]{2}{*}{ Entropy } & Maximize & 0.58554 & 1.31100 & 1.31100 & 1 & 1 & 1.20194 & 0.8497 \\
\hline & & & & & \multicolumn{3}{|c|}{ Global desirability: } & 0.5572 \\
\hline
\end{tabular}

Table 7

RSM for modeling global desirability $D_{M D E}$.

\begin{tabular}{|c|c|c|c|c|c|c|c|c|c|c|c|c|c|}
\hline$\omega_{1}$ & $\lambda_{1}$ & $\omega_{2}$ & $\lambda_{2}$ & $\omega_{3}$ & $\lambda_{3}$ & $D_{M D E}$ & Risk & Return & Entropy & $p_{1}$ & $p_{2}$ & $p_{3}$ & $p_{4}$ \\
\hline 0.10 & 1.0 & 5.05 & 1.0 & 5.05 & 5.5 & 0.99784 & 0.0326 & -0.0012 & 1.153 & 0.2902 & 0.1569 & 0.5279 & 0.025 \\
\hline 10.00 & 1.0 & 5.05 & 1.0 & 5.05 & 5.5 & 0.87558 & 0.0321 & -0.0016 & 12.731 & 0.3240 & 0.3255 & 0.3255 & 0.025 \\
\hline 0.10 & 10.0 & 5.05 & 1.0 & 5.05 & 5.5 & 0.99023 & 0.0326 & -0.0012 & 1.153 & 0.2902 & 0.1569 & 0.5279 & 0.025 \\
\hline 10.00 & 10.0 & 5.05 & 1.0 & 5.05 & 5.5 & 0.94140 & 0.0321 & -0.0016 & 1.273 & 0.3240 & 0.3255 & 0.3255 & 0.025 \\
\hline 0.10 & 1.0 & 5.05 & 10.0 & 5.05 & 5.5 & 0.99902 & 0.0326 & -0.0012 & 1.153 & 0.2902 & 0.1569 & 0.5279 & 0.025 \\
\hline 10.00 & 1.0 & 5.05 & 10.0 & 5.05 & 5.5 & 0.90644 & 0.0326 & -0.0012 & 1.153 & 0.2902 & 0.1569 & 0.5279 & 0.025 \\
\hline 0.10 & 10.0 & 5.05 & 10.0 & 5.05 & 5.5 & 0.99366 & 0.0326 & -0.0012 & 1.153 & 0.2902 & 0.1569 & 0.5279 & 0.025 \\
\hline 10.00 & 10.0 & 5.05 & 10.0 & 5.05 & 5.5 & 0.67653 & 0.0321 & -0.0016 & 12.731 & 0.3240 & 0.3255 & 0.3255 & 0.025 \\
\hline 5.05 & 1.0 & 0.10 & 5.5 & 0.10 & 5.5 & 0.99100 & 0.0321 & -0.0016 & 12.731 & 0.3240 & 0.3255 & 0.3255 & 0.025 \\
\hline 5.05 & 10.0 & 0.10 & 5.5 & 0.10 & 5.5 & 0.99485 & 0.0321 & -0.0016 & 12.731 & 0.3240 & 0.3255 & 0.3255 & 0.025 \\
\hline 5.05 & 1.0 & 10.00 & 5.5 & 0.10 & 5.5 & 0.94669 & 0.0324 & -0.0012 & 10.093 & 0.3328 & 0.0427 & 0.5995 & 0.025 \\
\hline 5.05 & 10.0 & 10.00 & 5.5 & 0.10 & 5.5 & 0.80278 & 0.0321 & -0.0014 & 10.104 & 0.3763 & 0.025 & 0.5737 & 0.025 \\
\hline 5.05 & 1.0 & 0.10 & 5.5 & 10.00 & 5.5 & 0.99100 & 0.0321 & -0.0016 & 12.731 & 0.3240 & 0.3255 & 0.3255 & 0.025 \\
\hline 5.05 & 10.0 & 0.10 & 5.5 & 10.00 & 5.5 & 0.99485 & 0.0321 & -0.0016 & 12.731 & 0.3240 & 0.3255 & 0.3255 & 0.025 \\
\hline 5.05 & 1.0 & 10.00 & 5.5 & 10.00 & 5.5 & 0.93407 & 0.0326 & -0.0012 & 1.153 & 0.2902 & 0.1569 & 0.5279 & 0.025 \\
\hline 5.05 & 10.0 & 10.00 & 5.5 & 10.00 & 5.5 & 0.75352 & 0.0321 & -0.0014 & 1.152 & 0.3573 & 0.0122 & 0.4954 & 0.025 \\
\hline 5.05 & 5.5 & 0.10 & 1.0 & 5.05 & 1.0 & 0.99737 & 0.0321 & -0.0016 & 12.731 & 0.3240 & 0.3255 & 0.3255 & 0.025 \\
\hline 5.05 & 5.5 & 10.00 & 1.0 & 5.05 & 1.0 & 0.76867 & 0.0321 & -0.0016 & 12.731 & 0.3240 & 0.3255 & 0.3255 & 0.025 \\
\hline 5.05 & 5.5 & 0.10 & 10.0 & 5.05 & 1.0 & 0.98811 & 0.0321 & -0.0016 & 12.731 & 0.3240 & 0.3255 & 0.3255 & 0.025 \\
\hline 5.05 & 5.5 & 10.00 & 10.0 & 5.05 & 1.0 & 0.78351 & 0.0325 & -0.0012 & 10.723 & 0.3167 & 0.0863 & 0.5720 & 0.025 \\
\hline 5.05 & 5.5 & 0.10 & 1.0 & 5.05 & 10.0 & 0.99880 & 0.0321 & -0.0016 & 12.731 & 0.3240 & 0.3255 & 0.3255 & 0.025 \\
\hline 5.05 & 5.5 & 10.00 & 1.0 & 5.05 & 10.0 & 0.88729 & 0.0321 & -0.0016 & 12.731 & 0.3240 & 0.3255 & 0.3255 & 0.025 \\
\hline 5.05 & 5.5 & 0.10 & 10.0 & 5.05 & 10.0 & 0.99229 & 0.0321 & -0.0016 & 12.731 & 0.3240 & 0.3255 & 0.3255 & 0.025 \\
\hline 5.05 & 5.5 & 10.00 & 10.0 & 5.05 & 10.0 & 0.83817 & 0.0326 & -0.0012 & 1.153 & 0.2902 & 0.1569 & 0.5279 & 0.025 \\
\hline 0.10 & 5.5 & 5.05 & 1.0 & 0.10 & 5.5 & 0.99030 & 0.0326 & -0.0012 & 1.153 & 0.2902 & 0.1569 & 0.5279 & 0.025 \\
\hline 10.00 & 5.5 & 5.05 & 1.0 & 0.10 & 5.5 & 0.92031 & 0.0321 & -0.0016 & 12.731 & 0.3240 & 0.3255 & 0.3255 & 0.025 \\
\hline 0.10 & 5.5 & 5.05 & 10.0 & 0.10 & 5.5 & 0.99576 & 0.0326 & -0.0012 & 1.153 & 0.2902 & 0.1569 & 0.5279 & 0.025 \\
\hline 10.00 & 5.5 & 5.05 & 10.0 & 0.10 & 5.5 & 0.81300 & 0.0321 & -0.0014 & 10.104 & 0.3763 & 0.025 & 0.5737 & 0.025 \\
\hline 0.10 & 5.5 & 5.05 & 1.0 & 10.00 & 5.5 & 0.99260 & 0.0326 & -0.0012 & 1.153 & 0.2902 & 0.1569 & 0.5279 & 0.025 \\
\hline 10.00 & 5.5 & 5.05 & 1.0 & 10.00 & 5.5 & 0.92031 & 0.0321 & -0.0016 & 12.731 & 0.3240 & 0.3255 & 0.3255 & 0.025 \\
\hline 0.10 & 5.5 & 5.05 & 10.0 & 10.00 & 5.5 & 0.99576 & 0.0326 & -0.0012 & 1.153 & 0.2902 & 0.1569 & 0.5279 & 0.025 \\
\hline 10.00 & 5.5 & 5.05 & 10.0 & 10.00 & 5.5 & 0.76016 & 0.0321 & -0.0014 & 11.721 & 0.3543 & 0.1399 & 0.4808 & 0.025 \\
\hline 5.05 & 1.0 & 5.05 & 5.5 & 0.10 & 1.0 & 0.92255 & 0.324 & -0.0012 & 0.9889 & 0.3292 & 0.025 & 0.6120 & 0.034 \\
\hline 5.05 & 10.0 & 5.05 & 5.5 & 0.10 & 1.0 & 0.86402 & 0.0321 & -0.0014 & 10.293 & 0.3806 & 0.0338 & 0.5606 & 0.025 \\
\hline 5.05 & 1.0 & 5.05 & 5.5 & 10.00 & 1.0 & 0.89661 & 0.0326 & -0.0012 & 1.153 & 0.2902 & 0.1569 & 0.5279 & 0.025 \\
\hline 5.05 & 10.0 & 5.05 & 5.5 & 10.00 & 1.0 & 0.71737 & 0.0321 & -0.0016 & 12.731 & 0.3240 & 0.3255 & 0.3255 & 0.025 \\
\hline 5.05 & 1.0 & 5.05 & 5.5 & 0.10 & 10.0 & 0.95582 & 0.0324 & -0.0012 & 10.363 & 0.3266 & 0.0604 & 0.5881 & 0.025 \\
\hline 5.05 & 10.0 & 5.05 & 5.5 & 0.10 & 10.0 & 0.90449 & 0.0321 & -0.0014 & 10.427 & 0.3771 & 0.0426 & 0.5553 & 0.025 \\
\hline 5.05 & 1.0 & 5.05 & 5.5 & 10.00 & 10.0 & 0.95161 & 0.0326 & -0.0012 & 1.153 & 0.2902 & 0.1569 & 0.5279 & 0.025 \\
\hline 5.05 & 10.0 & 5.05 & 5.5 & 10.00 & 10.0 & 0.80660 & 0.0321 & -0.0016 & 12.731 & 0.3240 & 0.3255 & 0.3255 & 0.025 \\
\hline 0.10 & 5.5 & 0.10 & 5.5 & 5.05 & 1.0 & 0.99479 & 0.0321 & -0.0014 & 11.721 & 0.3543 & 0.1399 & 0.4808 & 0.025 \\
\hline 10.00 & 5.5 & 0.10 & 5.5 & 5.05 & 1.0 & 0.99100 & 0.0321 & -0.0016 & 12.731 & 0.3240 & 0.3255 & 0.3255 & 0.025 \\
\hline 0.10 & 5.5 & 10.00 & 5.5 & 5.05 & 1.0 & 0.99260 & 0.0326 & -0.0012 & 1.153 & 0.2902 & 0.1569 & 0.5279 & 0.025 \\
\hline 10.00 & 5.5 & 10.00 & 5.5 & 5.05 & 1.0 & 0.62824 & 0.0321 & -0.0014 & 10.265 & 0.3762 & 0.0338 & 0.5650 & 0.025 \\
\hline 0.10 & 5.5 & 0.10 & 5.5 & 5.05 & 10.0 & 0.99702 & 0.0321 & -0.0014 & 11.721 & 0.3543 & 0.1399 & 0.4808 & 0.025 \\
\hline 10.00 & 5.5 & 0.10 & 5.5 & 5.05 & 10.0 & 0.99485 & 0.0321 & -0.0016 & 12.731 & 0.3240 & 0.3255 & 0.3255 & 0.025 \\
\hline 0.10 & 5.5 & 10.00 & 5.5 & 5.05 & 10.0 & 0.99576 & 0.0326 & -0.0012 & 1.153 & 0.2902 & 0.1569 & 0.5279 & 0.025 \\
\hline 10.00 & 5.5 & 10.00 & 5.5 & 5.05 & 10.0 & 0.74195 & 0.0321 & -0.0014 & 11.721 & 0.3543 & 0.1399 & 0.4808 & 0.025 \\
\hline 5.05 & 5.5 & 5.05 & 5.5 & 5.05 & 5.5 & 0.82544 & 0.0321 & -0.0014 & 11.721 & 0.3543 & 0.1399 & 0.4808 & 0.025 \\
\hline 5.05 & 5.5 & 5.05 & 5.5 & 5.05 & 5.5 & 0.82544 & 0.0321 & -0.0014 & 11.721 & 0.3543 & 0.1399 & 0.4808 & 0.025 \\
\hline 5.05 & 5.5 & 5.05 & 5.5 & 5.05 & 5.5 & 0.82544 & 0.0321 & -0.0014 & 11.721 & 0.3543 & 0.1399 & 0.4808 & 0.025 \\
\hline 5.05 & 5.5 & 5.05 & 5.5 & 5.05 & 5.5 & 0.82544 & 0.0321 & -0.0014 & 11.721 & 0.3543 & 0.1399 & 0.4808 & 0.025 \\
\hline 5.05 & 5.5 & 5.05 & 5.5 & 5.05 & 5.5 & 0.82544 & 0.0321 & -0.0014 & 11.721 & 0.3543 & 0.1399 & 0.4808 & 0.025 \\
\hline 5.05 & 5.5 & 5.05 & 5.5 & 5.05 & 5.5 & 0.82544 & 0.0321 & -0.0014 & 11.721 & 0.3543 & 0.1399 & 0.4808 & 0.025 \\
\hline
\end{tabular}




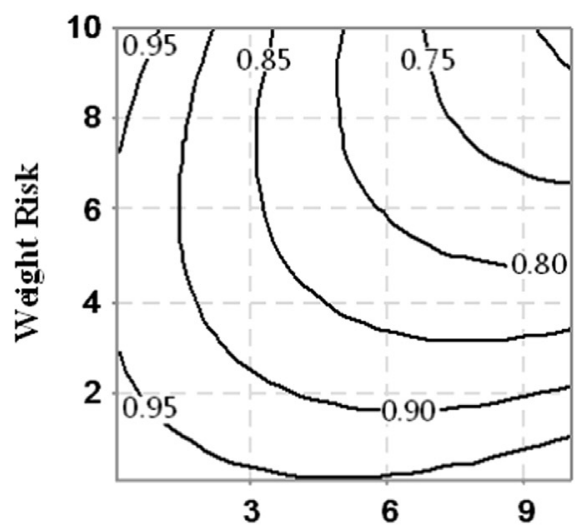

Weight Ret

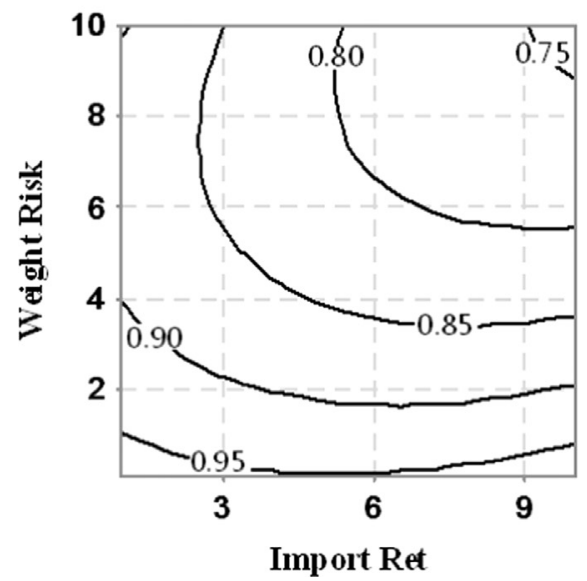

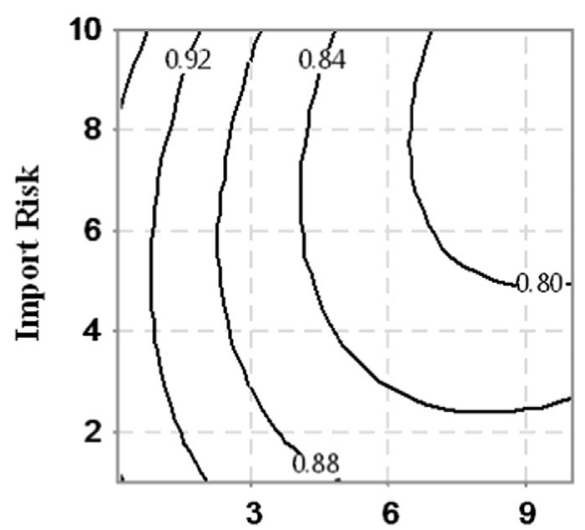

Weight Ret

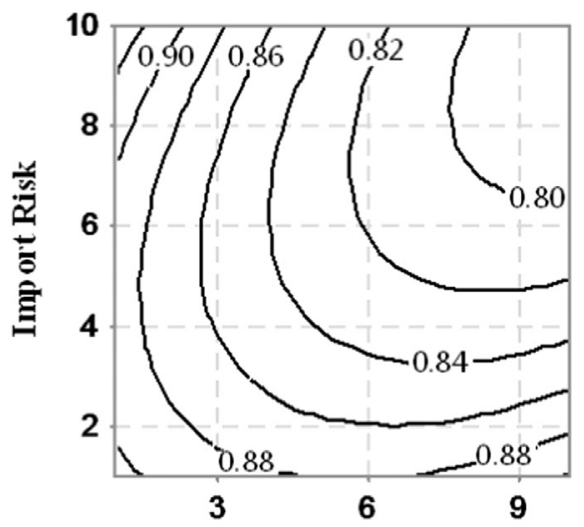

Imp ort Ret

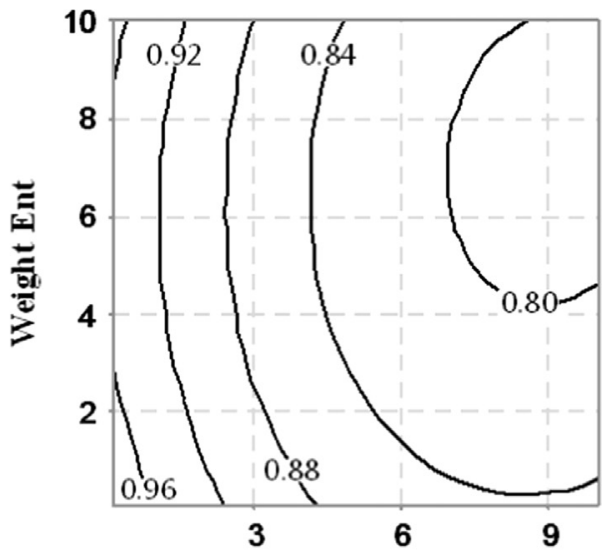

Weight Risk

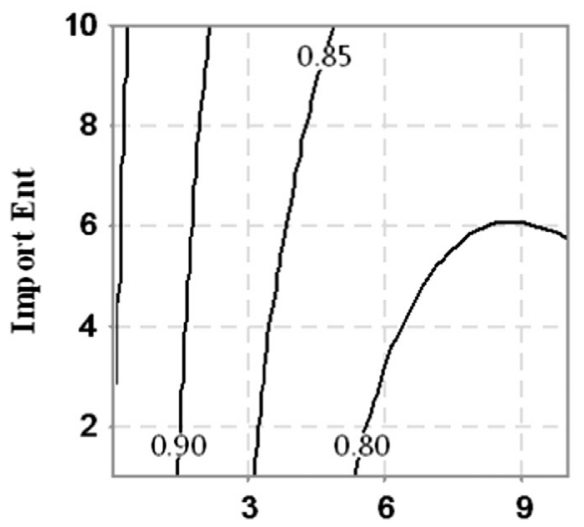

Weight Risk

Fig. 5. Contour plots of global desirability $D_{M D E}$ : interactions among the optimization parameters $\omega$ and $\lambda$.

\section{Computer-aided desirability tuning for portfolio optimization}

Dealing with a multiobjective optimization problem obtained through an experimental design, Derringer and Suich [42] improved the algorithm of desirability function of Harrington [43] to incorporate a set of transformations based on the limits imposed on the responses. Jeong and Kim [25], recognizing that the desirability tuning is not a trivial task, proposed a method to adjust the preference parameters of shape, bound and target, relaxing or tightening their values interactively. Extending Jeong and Kim's [25] strategy to experimentation field, a DOE strategy could be used to investigate the simultaneous changing in desirability parameters. This strategy, called as "Computer-aided desirability tuning", can be viewed as a kind of posterior decision maker's preference articulation in which an experimental design does not require all the feasible solutions of the posterior preference but only a few combinations. Departing from an initial choice for bounds $\left(L_{i}\right.$ and $\left.H_{i}\right)$ and targets $\left(T_{i}\right)$, weight $\left(\omega_{i}\right)$ and importance $\left(\lambda_{i}\right)$ parameters for each response can be simultaneously adjusted, according to a response surface design as BoxBehnken. If the number of parameters becomes larger, a screening strategy could be used such as Plackett-Burman, Taguchi, Fractional factorial or $D$-optimal designs.

Based on ARMA-GARCH modeling, computer-aided desirability tuning method consists of creating a mixture design for asset proportions in order to build risk, return and entropy functions. After that, the multiobjective portfolio problem can be optimized by using a desirability formulation as such:

$$
\begin{array}{cl}
\text { Maximize } & D_{M D E}=\sqrt[3]{\left[d\left(f_{1}\right)\right]^{\lambda_{1}} \times\left[d\left(f_{2}\right)\right]^{\lambda_{2}} \times\left[d\left(f_{3}\right)\right]^{\lambda_{3}}} \\
\text { s.t. : } & d^{n+1}\left(y_{i}\right) \geq D, \quad i=1,2, \ldots, k \\
& D \geq 0 \\
& x \in \Omega
\end{array}
$$

with:

$d\left[f_{1}\left(\sigma_{p}^{2}\right)\right]=\left\{\begin{array}{cc}0 & {\left[f_{1}\left(\sigma_{p}^{2}\right)\right]_{i}>U_{i}} \\ {\left[\frac{U_{i}-\left[f_{1}\left(\sigma_{p}^{2}\right)\right]_{i}}{U_{i}-T_{i}}\right]^{\omega}} & T_{i} \leq\left[f_{1}\left(\sigma_{p}^{2}\right)\right]_{i} \leq U_{i} \\ 1 & {\left[f_{1}\left(\sigma_{p}^{2}\right)\right]_{i}<T_{i}}\end{array}\right.$

$d\left[f_{2}(E(X))\right]=\left\{\begin{array}{cc}0 & {\left[f_{2}(E(X))\right]_{i}<L_{i}} \\ {\left[\frac{\left[f_{2}(E(X))\right]_{i}-L_{i}}{T_{i}-L_{i}}\right]^{\omega}} & L_{i} \leq\left[f_{2}(E(X))\right]_{i} \leq T_{i} \\ 1 & {\left[f_{2}(E(X))\right]_{i}>T_{i}}\end{array}\right.$

$d\left[f_{3}(S(X))\right]=\left\{\begin{array}{cc}0 & {\left[f_{3}(S(X))\right]_{i}<L_{i}} \\ {\left[\frac{\left[f_{3}(S(X))\right]_{i}-L_{i}}{T_{i}-L_{i}}\right]^{\omega}} & L_{i} \leq\left[f_{3}(S(X))\right]_{i} \leq T_{i} \\ 1 & {\left[f_{3}(S(X))\right]_{i}>T_{i}}\end{array}\right.$

where $d^{n+1}\left(y_{i}\right)$ is the desirability function of the $y_{i}$ on $(n+1)$ th run; $\Omega$ denotes the lower and upper bounds chosen for the proportions of each contract; $L_{i}$ is the desirability lower bound; 


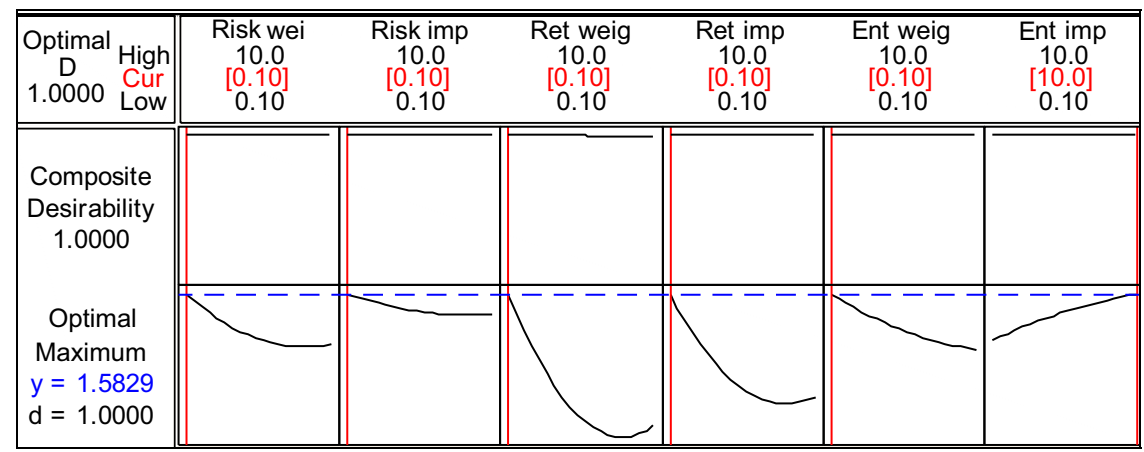

Fig. 6. Box-Behnken desirability $D_{R S M}$.

Table 8

Portfolio comparison between before and after computer-aided desirability tuning method.

\begin{tabular}{|c|c|c|c|c|c|c|c|c|}
\hline & & & & & Min & Max & Max & \\
\hline Portfolio & Dubai & China & Indon. & Venez. & Risk & Return & Entropy & Optimal Result \\
\hline Before & 0.0771 & 0.3397 & 0.1798 & 0.4034 & 0.0333 & 0.0117 & 1.2019 & 0.55719 \\
\hline After & 0.2211 & 0.2506 & 0.2412 & 0.2870 & 0.0325 & 0.0099 & 1.3073 & 0.99667 \\
\hline
\end{tabular}

$T_{i}$ is the desirability target; $H_{i}$ is the upper bound and; $\omega$ and $\lambda$ are the desirability weight and importance coefficients (risk aversion). In this decision-making scenario, upper or lower bounds assumed the mean value of the responses from each asset and the target was obtained by the individual optimization $\operatorname{Min} f_{i}(x)$.

Obviously, each different value of $\lambda_{i}$ and $\stackrel{x \in \Omega}{\omega_{i}}$ will conduct to different values of risk and return, depending on the risk aversion of each investor. A response surface design can be used to assess the values of weights and importance coefficients that maximize the desirability function $D_{M D E}$. Thus, $D_{M D E}$ can be adjusted by a second-order response surface model for $\omega_{i}$ and $\lambda_{i}$, such as:

$D_{M D E}(\omega, \lambda)=\beta_{0}+\sum_{i=1}^{k} \beta_{i} x_{i}+\sum_{i=1}^{k} \beta_{i i} x_{i}^{2}+\sum \sum_{i<j} \beta_{i j} x_{i} x_{j}+\varepsilon$

where $x_{i}$ are the desirability weights $(\omega)$ and the importance coefficients $(\lambda)$ assigned to risk, return and entropy. Hence, Eqs. (35) and (36) determine how to obtain the optimal parameters $\left(\lambda_{i}\right.$ and $\left.\omega_{i}\right)$ for being set at the multiobjective portfolio problem $\left(D_{M D E}\right)$ in Eqs. (30)-(33).

$$
\begin{array}{cc}
\text { Maximize } & D_{R S M}=\left[\frac{D_{M D E}(\omega, \lambda)-L}{T-L}\right]^{\varpi} \\
\text { s.t. : } & \omega, \lambda \in \Xi
\end{array}
$$

where:

$D_{R S M}=\left\{\begin{array}{cc}0 & D_{M D E}(\omega, \lambda)<L \\ {\left[\frac{D_{M D E}(\omega, \lambda)-L}{T-L}\right]^{\varpi}} & L \leq D_{M D E}(\omega, \lambda) \leq T \\ 1 & D_{M D E}(\omega, \lambda)>T\end{array}\right.$

where $D_{R S M}$ is the desirability function based on Box-Behnken design; $\Xi$ denotes the experimental region constraint; $L$ is the desirability lower bound; $T$ is the desirability target obtained by $\operatorname{Min} D_{M D E}(\omega, \lambda)$ and; $\varpi$ is the desirability weight applied to $D_{R S M}$ optimization.

Finally, optimal weights and importance coefficients from Eq. (35) must be applied to Eqs. (30)-(33) in order to estimate the optimal portfolio. Computer-aided desirability tuning method is schematically summarized in Fig. 1. Next section presents a case study with ARMA-GARCH weekly world crude oil spot prices and returns to numerically illustrate the proposed method.

\section{Illustrative example}

\subsection{Choose heteroskedastic assets}

To attend the goals of this paper, the assets that will be comprised as components of the mixture design experiment (MDE) were chosen from weekly data of world crude oil (FOB) spot prices (dollars per barrel) covering January 2nd, 1998 to October 15th, 2011 obtained from Energy Information Administration-EIA ${ }^{1}$ totalizing 718 observations each. To analyze and treat the time series for the portfolio, four assets were chosen for comprise the portfolio using their prices in oil-exporting from Organization of Petroleum Exporting Countries (OPEC) and nonOPEC: Asia Dubai Fateh, China Daqing, Indonesia Minas and Venezuela Tia Juana. Stationary requirements for the analysis were obtained by $\log$ return $\left(\varepsilon_{t}=\log \left[p_{t} / p_{t-1}\right]\right)$, where $p_{t}$ and $p_{t-1}$ are current and considered one-period lagged prices. Each of these assets will be the mixture design components.

An important step in the proposed approach is the verification of series' behavior. Fig. 2 shows the portfolio's time series for one of the mixture components.

In this plot the characteristic of the series presents some heteroskedasticity. This can be seen at the significance of the signs on return series and also on the original's time series volatility. Similar findings are present on the other components of the portfolio. Table 1 presents a descriptive return series summary statistics. The negative values of skewness reveal high probability of large decreases. In other way, a high value of the kurtosis indicates that extreme price changes normally occur.

In order to quantify the heteroskedasticity, Table 2 presents statistical tests of hypothesis between the pair of series. LjungBox-Pierce $Q$-test does not reject the presence of autocorrelation in the series of returns. Additionally, Engle's ARCH test suggests the conditional correlation of residuals (heteroskedasticity or ARCH effects).

Fig. 3a exhibits the first and third lags autocorrelation, depicting the existence of effects that justify the adoption of an ARMA ( $p$, $q$ ) model. The autocorrelation of the squared returns shown on Fig. $3 \mathrm{~b}$ indicates heteroskedasticity, when the process variance has

\footnotetext{
${ }^{1}$ Available at: http://www.eia.gov/dnav/pet/pet_pri_wco_k_w.htm.
} 

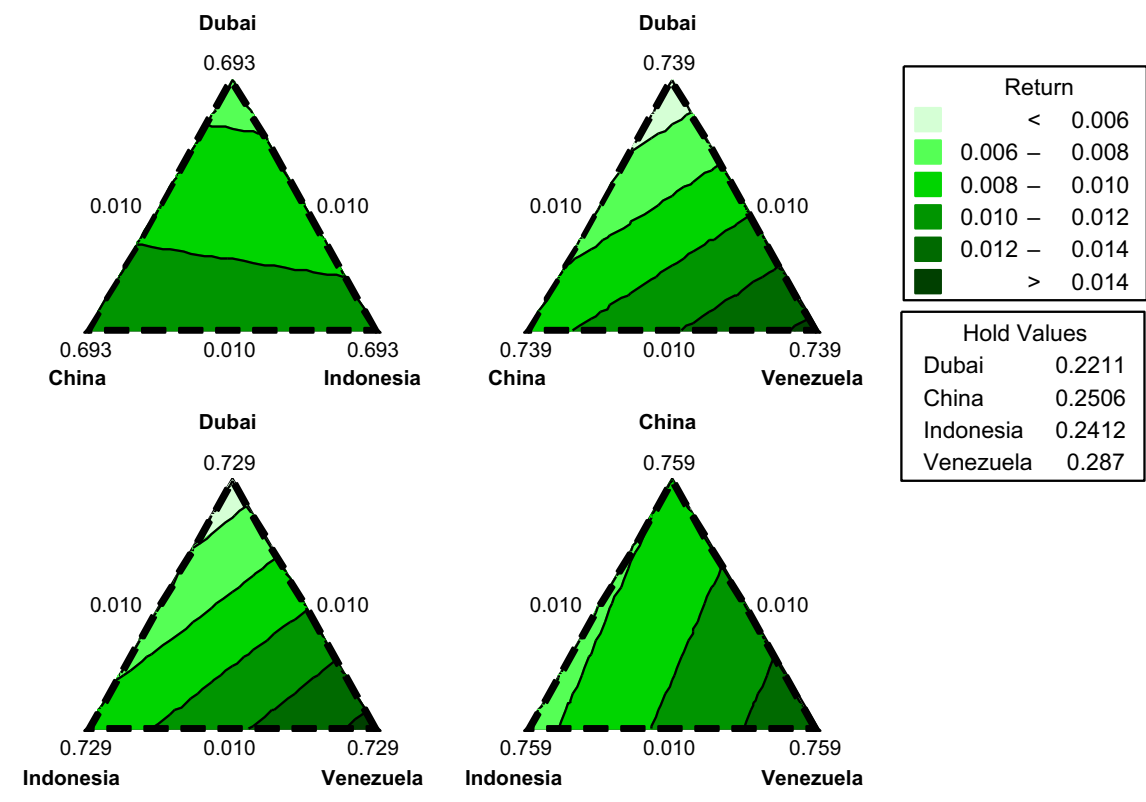

Fig. 7. Contour plot for Portfolio's return.

some correlation and conditional structure, also denoting the necessity of use of GARCH model. Since the series' behavior is heteroskedastic, in the next step, the one-step-ahead values of return and risk will be predicted using an ARMA-GARCH model.

\subsection{Forecast $\hat{\mu}$ and $\hat{\sigma}^{2}$ by ARMA-GARCH model}

The ARMA-GARCH parameters for each asset are presented on Table 3. At this point, adopting the appropriate ARMA-GARCH model for each market, it is possible to forecast values of mean and standard deviation for each asset with one-step-ahead for $\hat{\sigma}_{t}^{2}$ and $\hat{y}_{i, t}$, as presented on Table 4 . These values will be used to compose the portfolio's risk and return with constant conditional correlation calculated with the predicted one-step-ahead variance terms, as suggested by Eq. (17).

\subsection{Create a MDE for selected assets}

For the completion of the research objective, it was adopted an Extreme Vertices Mixture Design for 4 assets and a third order polynomial degree. The proportions of each asset in the mixture design were defined in a constrained range from a minimum of $5 \%$ to a maximum of $85 \%$. Using the one-step-ahead forecast for $\hat{\sigma}_{t}^{2}$ and $\hat{y}_{i, t}$ for each asset, it was built the design for risk, return and entropy whose values were obtained using Eqs. (23)-(25), respectively, as shown in Table 5.

Using Eq. (29), response surfaces were built for each portfolio property using the OLS algorithm, leading to the follow objective functions:

$$
\begin{aligned}
\left\{f_{1}\left(\sigma_{t}^{2}\right)\right\}_{\text {Portfolio }}= & 0.0326 p_{1}+0.0356 p_{2}+0.0370 p_{3} \\
& +0.0375 p_{4}-0.01185 p_{1} p_{2} \\
& -0.01303 p_{1} p_{3}-0.00623 p_{1} p_{4}-0.001643 p_{2} p_{3} \\
& -0.01295 p_{2} p_{4}-0.0134 p_{3} p_{4}
\end{aligned}
$$

$\left\{f_{2}[E(\mathbf{x})]\right\}_{\text {Portfolio }}=-0.0034 p_{1}-0.0012 p_{2}+0.0001 p_{3}-0,0041 p_{4}$

$$
\begin{aligned}
\left\{f_{3}[S(\mathbf{x})]\right\}_{\text {Portfolio }}= & 0.1123 p_{1}+0.1123 p_{2}+0.1123 p_{3} \\
& +0.1123 p_{4}+3.4016 p_{1} p_{2}
\end{aligned}
$$

$$
\begin{aligned}
& +3.4016 p_{1} p_{3}+3.4016 p_{1} p_{4}+3.4016 p_{2} p_{3} \\
& +3.4016 p_{2} p_{4}+3.4016 p_{3} p_{4}
\end{aligned}
$$

As could be seen, the application of MDE considers several scenarios and predicts how each asset improves the investor gain. Fig. 4 presents a mixture models for (a) risk, (b) return and (c) entropy of the portfolio showing the influence of proportions in variation of portfolio's performance.

The desirability algorithm can be applied to optimize this portfolio. Since the multiple objective functions are established, it is necessary to define values for $H_{i}, T_{i}$ and $L_{i}$ for desirability running. In this case, when the objective is to maximize or minimize the response, it was adopted the mean value of the responses from each asset for upper or lower bounds. To obtain $T_{i}$ values, an individual optimization, $\operatorname{Min} f_{i}(x)$, was conducted using the Generalized Reduced Gradient ${ }^{x}$ (GRG) algorithm available at Solver of Excel ${ }^{\circledR}$. The components used at GRG were obtained after analyzing statistically the mixture models and searching for the higher $R^{2}$ (adj.) for each response. In the first run, it was chosen a value equal to 1 for both $\omega_{i}$ and $\lambda_{i}$, which indicates the absence of a decision criteria. Table 6 presents bound, target, weight and importance parameters applied to desirability algorithm before the tuning procedure. For this scenario, global desirability was $55.72 \%$ and the optimal asset proportions were $7.71 \%$ (Dubai), 33.97\% (China), 17.98\% (Indonesia) and 40.34\% (Venezuela).

\subsection{Create a RSM for risk, return and entropy's weight and importance}

As noted in Table 6, the first desirability trial was not wellsucceed suggesting that the computer-aided desirability tuning may be employed. Practitioners are usually more comfortable defining bounds and targets parameters since they are part of their daily work [25]. These parameters were not included into the tuning procedure so that they were held constant, according to previous step 4.3. Notwithstanding weight and importance parameters must also be set, this decision-making process is not a trivial task. Thus, the objective of this step is to generate the best values for $\omega_{i}$ and $\lambda_{i}$ to be used in the last MDE. A Box-Behnken was adopted as an experimental design considering 6 factors, being $\omega_{i}$ and $\lambda_{i}$ for each component of risk, return and entropy, with further 
6 center points. This response surface design generated the 54 runs described in Table 7. The values of $\omega_{i}$ and $\lambda_{i}$ were chosen in the range from 0.1 to 10 and from 1 to 10 , respectively. The control variables were set as follows: $\omega_{1}$ represents the desirability's weight for portfolio risk; $\lambda_{1}$ is the desirability's importance for portfolio risk; $\omega_{2}$ is the desirability's weight portfolio return; $\lambda_{2}$ is the desirability's importance for portfolio return; $\omega_{3}$ is the desirability's weight for entropy and; $\lambda_{3}$ is the desirability's importance for portfolio entropy.

4.5. Run $D_{M D E}$ based on RSM's $\omega_{i}$ and $\lambda_{i}$ registering responses on RSM arrange

According to 54 runs in Table 7, $\omega_{i}$ and $\lambda_{i}$ were used to set the desirability algorithm $D_{M D E}$ in Eqs. (30)-(33). The results for global desirability $D_{M D E}$, risk, return, entropy and asset proportions were also stored in Table 7. After testing several linear and nonlinear models, the full quadratic model for global desirability $D_{M D E}$, in Eq. (40), has presented the best fit (adjusted $R^{2}=88.5 \%$ ) by using Eq. (34). As can be seen in Fig. 5, the behavior of global desirability $D_{M D E}$ depends on the quadratic and interaction effects among the individual desirability parameters.

$$
\begin{aligned}
\hat{\mathrm{D}}_{M D E}(\mathbf{x})= & 0.8254-0.0772 \omega_{1}-0.0224 \lambda_{1} \\
& -0.0736 \omega_{2}-0.0387 \lambda_{2}-0.0161 \omega_{3}+0.0217 \lambda_{3}+ \\
& +0.0496 \omega_{1}^{2}+0.0309 \lambda_{1}^{2}+0.0412 \omega_{2}^{2}+0.0251 \lambda_{2}^{2} \\
& +0.0260 \omega_{3}^{2}+0.0009 \lambda_{3}^{2}+ \\
& -0.0023 \omega_{1} \lambda_{1}-0.0765 \omega_{1} \omega_{2}-0.0415 \omega_{1} \lambda_{2} \\
& -0.0077 \omega_{1} \omega_{3}+0.0174 \omega_{1} \lambda_{3}-0.0322 \lambda_{1} \omega_{2}+ \\
& -0.0367 \lambda_{1} \lambda_{2}-0.0069 \lambda_{1} \omega_{3}-0.0077 \lambda_{1} \lambda_{3} \\
& -0.0189 \omega_{2} \lambda_{2}-0.0069 \omega_{2} \omega_{3}+ \\
& +.0140 \omega_{2} \lambda_{3}-0.0157 \lambda_{2} \omega_{3}+0.0052 \lambda_{2} \lambda_{3}+0.0088 \omega_{3} \lambda_{3}
\end{aligned}
$$

\subsection{Run $D_{R S M}$ to find the best $\omega_{i}$ and $\lambda_{i}$ for portfolio optimization}

Since the response surface for global desirability function $\left(D_{M D E}\right)$ is established, a nonlinear optimization routine should be used to maximize this response. Considering the desirability function based on the response surface design, Eqs. (35) and (36), the values for $H_{i}, L_{i}$ and $T_{i}$ are obtained in the same way of the step 4.3. In this optimization routine there is only one response to be maximized, the global desirability $D_{M D E}$. Fig. 6 shows the best $\omega_{i}$ and $\lambda_{i}$ parameters to optimize the $D_{M D E}$ and, then, to find the optimal portfolio.

\subsection{In $M D E$, run the final desirability $\left(D_{M D E}\right)$ to find the optimal portfolio}

In order to obtain an optimal portfolio, the last routine was processed by using $H_{i}, L_{i}$ and $T_{i}$ from step 4.3, and $\omega_{i}$ and $\lambda_{i}$ from step 4.6. Table 8 presents the comparison results before and after computer-aided desirability tuning with an improvement of 78.87\%. The optimal portfolio obtained in this condition was distributed as 22.11\% (Dubai), 25.06\% (China), 24.12\% (Indonesia) and $28.70 \%$ (Venezuela). The balanced distribution of assets was possible after the inclusion of the Shannon's entropy. Fig. 7 illustrates the mixture contour plot for returns of weekly world crude oil spot prices portfolio.

\section{Conclusions}

This paper has presented a computer-aided desirability tuning method for multiobjective portfolio optimization. First, weekly world crude oil spot prices were adjusted to an ARMA-GARCH model in order to obtain the expected portfolio risk and return. Second, mixture design was adopted to investigate and model risk, return and entropy in relation to the asset proportions. Third, the mixture models were optimized using desirability functions. Eventually, response surface design has been applied to model global desirability function $\left(D_{M D E}\right)$ and to set optimal parameters for portfolio selection.

The proposed method was able to reduce subjectivity and margin of errors from decision makers. Comparing computeraided method's performance to the results with no decision maker preference, the global desirability was substantially enhanced (about 79\%). Similarly, 99.68\% of global desirability has insured investor's interest by mitigating risk and raising diversity of the portfolio. It is also essential to emphasize that the interactions among desirability parameters have greatly influenced the algorithm performance. As could be seen in Figs. 6, $\omega 1$ and $\omega 2$ were the most significant parameters for the global desirability performance, mainly due to tighter bounds assigned to the responses risk and return.

Further works could add bounds and targets for each response as factors into the designed experiments in order to quantify their relationship with weight and importance parameters. Although the numerical results are related to a specific crude oil portfolio, the computer-aided desirability tuning procedure can be properly extended to other portfolio selection with the aim of obtaining not only an adequate return but also low level of risk. Another further contribution would implement the general idea of this tuning procedure for different multiobjective optimization methods based on decision maker's preference such as: utility function, global criterion, goal attainment, normal boundary intersection, and others. In addition, other objective functions could be included in the optimization algorithm such as liquidity, portfolio cost and skewness.

\section{Acknowledgements}

The authors would like to express their gratitude to Brazilian Governmental Agencies CAPES, CNPq and FAPEMIG that supported this research.

\section{References}

[1] García-Martos C, Rodríguez J, Sánchez MJ. Modelling and forecasting fossil fuels, $\mathrm{CO}_{2}$ and electricity prices and their volatilities. Appl Energy $2013 ; 10: 363-75$.

[2] Bollerslev T. Generalized autoregressive conditional heteroskedasticity. J Econom 1986;31:307-27.

[3] Ghosh S. Examining crude oil price-exchange rate nexus for India during the period of extreme oil price volatility. Appl Energy 2011;88:1886-9.

[4] Charles A, Darné O. Volatility persistence in crude oil markets. Energy Policy 2014;65:729-42.

[5] Mohammadi H, Su L. International evidence on crude oil price dynamics: applications of ARIMA-GARCH models. Energy Econ 2010;32:1001-8.

[6] Hou A, Suardi S. A nonparametric GARCH model of crude oil price return volatility. Energy Econ 2012;34:618-26.

[7] Chang T-H, Su HM, Chiu CL. Value-at risk estimation with the optimal dynamic biofuel portfolio. Energy Econ 2011:33:264-72.

[8] Markowitz H. Portfolio selection. J Finan 1952;7:77-91.

[9] Markowitz H. Portfolio selection: efficient diversification of investments. New York: John Wiley and Sons; 1959.

[10] Delarue E, De Johghe C, Belmans R, D'haeseleer W. Applying portfolio theory to the electricity sector: energy versus power. Energy Econ 2011;33:12-23.

[11] Li Z, Shu H. Optimal portfolio selection with liability management and Markov switching under constrained variance. Comput Math Appl 2011:61:2271-7.

[12] Diongue AK, Guégan D, Vignal V. Forecasting electricity spot market prices with a k-factor GIGARCH process. Appl Energy 2009;86:505-10.

[13] Bauwens L, Omrane WB, Rengifo E. Intradaily dynamic portfolio selection. Comput Stat Data Anal 2010:54:2400-18.

[14] Hung J-C, Lee M-C, Liu H-C. Estimation of value-at-risk for energy commodities via fat-tailed GARCH models. Energy Econ 2008;30:1173-91.

[15] Huang J-J, Lee K-J, Liang H, Lin W-F. Estimating value at risk of portfolio by conditional copula-GARCH method. Ins Math Econ 2009;45:315-24. 
[16] Higgs H. Modelling price and volatility inter-relationships in the Australian wholesale spot electricity markets. Energy Econ 2009;31:748-56.

[17] Varga-Haszonits I, Kondor I. Noise sensitivity of portfolio selection in constant conditional correlation GARCH models. Physica A 2007;385:307-18.

[18] Chang C-L, McAleer M, Tansuchat R. Analyzing and forecasting volatility spillovers, asymmetries and hedging in major oil markets. Energy Econ 2010;32:1445-55.

[19] Hlouskova J, Schmidheiny K, Wagner M. Multistep predictions for multivariate GARCH models: closed form solution and the value for portfolio management. J. Empirical Finance 2009;16:330-6.

[20] Kolm PN, Tutuncu R, Fabozzi FJ. 60 Years of portfolio optimization: practical challenges and current trends. Eur J Oper Res 2014;234:356-71.

[21] Zhou R, Cai R, Tong G. Applications of entropy in finance: a review. Entropy $2013 ; 15: 4909-31$.

[22] Philippatos GC, Wilson CJ. Entropy, market risk, and the selection of efficient portfolios. Appl Econ 1972:4:209-20.

[23] Yu JR, Lee WY, Chiou WJP. Diversified portfolios with different entropy measures. Appl Math Comput 2014;241:47-63.

[24] Oliveira FA, Paiva AP, Lima JWM, Balestrassi PP, Mendes RRA. Portfolio optimization using Mixture Design of Experiments: scheduling trades within electricity markets. Energy Econ 2011;33:24-32.

[25] Jeong IJ, Kim KJ. An interactive desirability function method to multiresponse optimization. Eur J Oper Res 2009;195:412-26.

[26] Anagnostopoulos KP, Mamanis G. A portfolio optimization model with three objectives and discrete variables. Comput Oper Res 2010;37:1285-97.

[27] Pham HT, Yang BS. Estimation and forecasting of machine health condition using ARMA/GARCH model. Mech Syst Sig Process 2010;24:546-58.

[28] Bollerslev T. Modelling the coherence in short-run nominal exchange rates: a multivariate generalized ARCH model. Rev Econ Stat 1990;72:498-505.

[29] Engle R. Dynamic conditional correlation: a sample class of multivariate generalized autoregressive conditional heteroskedasticity models. J Bus Econ Stat 2002;20:339-50.
[30] Asai M, McAleer M. The structure of dynamic correlations in multivariate stochastic volatility models. J Econometrics 2009;150:182-92.

[31] Kroner KF, Ng VK. Modeling asymmetric movements of asset prices. Rev Finan Stud 1998;11:817-44.

[32] Bera AK, Park SY. Optimal portfolio diversification using the maximum entropy principle. Econom Rev 2008;27:484-512.

[33] Jana P, Roy TK, Mazumder SK. Multi-objective mean-variance-skewness model for portfolio optimization. Adv Model Optim 2007;9:181-93.

[34] Usta I, Kantar YM. Mean-variance-skewness-entropy measures: a multiobjective approach for portfolio selection. Entropy 2011;13:117-33.

[35] Samanta B, Roy TK. Multi-objective portfolio optimization model. Tamsui Oxf ] Math Sci 2005;21:55-70.

[36] Hickey EA, Carlson JL, Loomis D. Issues in the determination of the optima portfolio of electricity supply options. Energy Policy 2010;38:2198-207.

[37] Grubb M, Butler L, Twomey P. Diversity and security in UK electricity generation: the influence of low-carbon objectives. Energy Policy 2006;34:4050-62.

[38] Krokhmal P, Zabarankin M, Uryasev S. Modeling and optimization of risk. Surv Oper Res Manage Sci 2011;16:49-66

[39] Moreno B, García-Álvarez MT, Ramos C, Fernández-Vázquez E. A genera maximum entropy econometric approach to model industrial electricity prices in Spain: a challenge for the competitiveness. Appl Energy 2014;135:815-24.

[40] Stirling A. Diversity and ignorance in electricity supply investment. Energy Policy 1994;22:195-216.

[41] Cornell JA. Experiments with mixtures: design, models, and the analysis of mixture data. New York: John Wiley and Sons; 2002.

[42] Derringer R, Suich R. Simultaneous optimization of several response variables. J Qual Technol 1980;12:214-9.

[43] Harrington EC. The desirability function. Ind Qual Control 1965;21:494-8. 